\title{
Water-soluble polysaccharides from Opuntia stricta Haw. fruit peels: recovery, identification and evaluation of their antioxidant activities**
}

\author{
Mohamed Koubaa ${ }^{1 *}$, Ameni Ktata ${ }^{2}$, Francisco J. Barba ${ }^{3 *}$, Nabil Grimi ${ }^{1}$, Houcine Mhemdi ${ }^{1}$, \\ Fatma Bouaziz ${ }^{2}$, Dorra Driss ${ }^{2}$, and Semia Ellouz Chaabouni ${ }^{2,4}$
}

${ }^{1}$ Sorbonne Universités, Université de Technologie de Compiègne, Laboratoire Transformations Intégrées de la Matière Renouvelable (UTC/ESCOM, EA 4297 TIMR), Centre de Recherche de Royallieu, B.P. 20529, 60205 Compiègne Cedex, France

${ }^{2}$ Enzyme Bioconversion Unit (UR13ES74), National School of Engineering, P.O. Box 1173-3038, Sfax University, Tunisia

${ }^{3}$ Faculty of Pharmacy, Nutrition and Food Science Area, Universitat de València, Avda. Vicent Andrés Estellés, s/n. 46100 Burjassot, Spain

${ }^{4}$ Common Service Unit of Bioreactor coupled with an ultrafilter, National School of Engineering, P.O. Box 1173-3038,

Sfax University, Tunisia

Received March 11, 2015; accepted June 1, 2015

\begin{abstract}
A b s t r a c t. Opuntia stricta Haw. is considered as one of the most common cactus plant growing in Tunisia. Extracting valuable compounds from its fruit peel, considered as by-product, is drawing more and more attention, making it on the verge of commercialization. Water-soluble polysaccharides were extracted from Opuntia stricta Haw. peels, and their chemical composition assessed using thin layer chromatography. The antioxidant activities of the extracted polysaccharides were assessed using 2,2-diphenyl-1-picrylhydrazyl free radical scavenging activity, total antioxidant activity and reducing power capacity. The extraction yield of water-soluble polysaccharides was $7.53 \pm 0.86 \%$. The chemical composition revealed the presence of rhamnose, arabinose, glucose, mannose, galactose and galacturonic acid. The infra-red spectroscopic analysis showed a similar structure to that of Opuntia ficus-indica polysaccharide peels. Additionally, the extracted polysaccharides exhibited high antioxidant activities. In fact, the free radical scavenging activity (half inhibition concentration $=6.5 \mathrm{mg} \mathrm{ml}^{-1}$ with $94.9 \%$ inhibition at $50 \mathrm{mg} \mathrm{ml}^{-1}$ ), the total antioxidant activity (100 $\mu \mathrm{g}$ ascorbic acid equivalent at $50 \mathrm{mg}$ polysaccharides) and the reducing power capacity (absorbance $700 \mathrm{~nm}=0.7$ at $50 \mathrm{mg} \mathrm{ml}^{-1}$ ), appeared to be interesting compared to natural and synthetic antioxidants. Therefore, watersoluble polysaccharides from Opuntia stricta Haw. fruit peels could be a natural alternative to replace synthetic antioxidants.

K e y w o r d s: Opuntia stricta Haw. peels, polysaccharide extraction, water-soluble polysaccharides, antioxidant activity
\end{abstract}

\section{INTRODUCTION}

Plant extracts constitute natural sources of antioxidant compounds (Dent et al., 2013; Polya, 2003; Šic Žlabur et $a l ., 2015)$. They are hence used in numerous applications

*Corresponding author e-mail: koubaa.mohamed@gmail.com, francisco.barba@uv.es

**This work was funded by the Ministry of Higher Education and Scientific Research of Tunisia. ranging from phytotherapy to the modern food industries (Belton et al., 2003). The extraction of antioxidant molecules represents an important way of agricultural waste valorisation, especially due to the technological advances in molecular separation and identification (Roselló-Soto et al., 2015; Wijngaard et al., 2012), as well as due to the uses of emerging technologies replacing thus the conventional ones (Galanakis, 2012, 2013). Numerous antioxidant molecules derived from plant extracts have been widely used as additives in food formulation (Sinha et al., 2008), in part due to their biological activities (Roselló-Soto et al., 2015). To address the problems of oxidation and contamination of foodstuffs, many synthetic antioxidant molecules are often added. However, regarding their potential toxicity and carcinogenicity, they have been restricted by legislation in many countries (Madhavi et al., 1996). Hence, their replacement by natural molecules has been widely studied. The antioxidant potential of different polysaccharides has been demonstrated. Moreover, they are harmless and do not cause side effects (Warrand, 2006). In addition, these high molecular weight polymers may exhibit therapeutic properties eg anti-tumor, anti-inflammatory, and anti-microbial activities (Caili et al., 2007; Chen et al., 2008; Krichen et al., 2015; Leung et al., 2006; Mokni Ghribi et al., 2015). All of these activities and others are closely related to the physicochemical properties of each polysaccharide molecule such as the type of the sugar residues, the chemical composition, the molecular weight and the degree of branching. Numerous research groups have been interested

(C) 2015 Institute of Agrophysics, Polish Academy of Sciences 
in extracting polysaccharides from agricultural and industrial by-products for their valorisation (Galanakis, 2011; Galanakis and Schieber, 2014; Sila et al., 2014a).

Extracting polysaccharides from opuntia fruit peels, especially from the ficus-indica species, has been studied due to its high availability as agro-industrial by-product in arid and semi-arid regions (Habibi et al., 2004; Majdoub et al., 2010). In Tunisia, Opuntia stricta Haw. is the second widespread cactus plant growing after $O$. ficus-indica. Numerous studies have been conducted on O. stricta Haw. peels, such as the extraction and characterisation of polyphenols, flavonoids, betacyanins (Yeddes et al., 2013) and dyes (Obón et al., 2009), making it on the verge of commercialization.

In this work, chemical composition of Opuntia stricta Haw. peels were investigated. Water-soluble polysaccharides (WSP) were extracted from O. stricta Haw. peels, their structure was investigated using Fourier transform infrared spectroscopy, and their chemical composition was assessed using thin layer chromatography. DPPH (2,2-diphenyl-1-picrylhydrazyl) free radical scavenging activity, total antioxidant activity, and reducing power capacity of the extracted WSP were also studied.

\section{MATERIAL AND METHODS}

Potassium ferricyanide was purchased from Loba Chemie (India). Sodium phosphate, sodium tetraborate, sodium dodecyl sulphate, ferric chloride, DPPH, trichloroacetic acid, trifluoroacetic acid, Tris, petroleum ether, glucose, arabinose, mannose, xylose, rhamnose, galactose, galacturonic acid, polygalacturonic acid, cellulose, citrus peel pectin and beechwood xylan were obtained from Sigma-Aldrich (France). Sulphuric acid and ethanol were obtained from Sharlab (Spain). Ammonium molybdate was obtained from NenTech Ltd (United Kingdom).

Opuntia stricta Haw. fruits were collected in the suburb of Sfax city, Tunisia, in February 2014. They were composed of $69 \%$ peel, $21 \%$ pulp and $10 \%$ seeds. The peels were separated manually from the pulps and the seeds, and then blended using a kitchen mixer. The obtained viscous peel juice was frozen at $-20^{\circ} \mathrm{C}$ until analysis.

Dry matter was determined according to AFNOR standards (AFNOR, 1982). Total nitrogen content was determined by Kjeldahl method (AFNOR, 1977). Soluble proteins were extracted using $1 \mathrm{~g}$ of peel juice mixed with $1 \mathrm{ml}$ of extraction buffer (20 mM Tris- $\mathrm{HCl}$ (pH 7.5), $150 \mathrm{mM} \mathrm{NaCl}$ and $1 \%$ sodium dodecyl sulphate). The mixture was vigorously vortexted for $10 \mathrm{~min}$, then centrifuged for $15 \mathrm{~min}$ at 13,000 r.p.m. The extraction was repeated four times and the supernatants were pooled together. The extracted proteins were quantified using Bradford (1976) method and BSA as standard curve. Lipid content was determined according to Soxhlet method (AFNOR, 1981), using $1 \mathrm{~g}$ of dried peels for $12 \mathrm{~h}$ at $105^{\circ} \mathrm{C}$, and petrole- um ether as solvent. Total sugar content was determined according to Dubois et al. (1956). Total ash was determined by the combustion of $5 \mathrm{~g}$ peel juice in a muffle furnace at $550^{\circ} \mathrm{C}$ for $4 \mathrm{~h}$. After dry ashing, the mineral composition ( $\mathrm{Na}, \mathrm{Mg}$ and $\mathrm{Ca}$ ) was determined by flame atomic absorption spectrometry (Analytic Jena ZEEnit 700 spectrometer, USA) (Jorhem, 2000).

Water-soluble polysaccharides (WSP) were extracted from $O$. stricta Haw. peels as described previously with slight modifications (Ding et al., 2012). $100 \mathrm{~g}$ of O. stricta Haw. peel juice was mixed with $500 \mathrm{ml}$ distilled water in 11 round bottom flask. The mixture was then boiled with reflux for $4 \mathrm{~h}$ using heating mantle. The mixture was then recovered, filtered through Whatman paper using Büchner funnel. The pellet was then extracted a second time under the same conditions and the filtrates containing WSP were pooled and concentrated 20 times using a rotary evaporator system at $50^{\circ} \mathrm{C}$. WSP were recovered overnight by adding $100 \mathrm{ml}$ absolute ethanol at $-20^{\circ} \mathrm{C}$, followed by $15 \mathrm{~min}$ centrifugation at 5000 r.p.m. Five washing steps were performed in order to remove the colorants from the extracted polysaccharides. Each step consisted of resolubilising the WSP in $20 \mathrm{ml}$ distilled water, followed by adding one volume of absolute ethanol, an overnight precipitation and a centrifugation step as described above. A dialysis step was performed on the recovered WSP using bi-distilled water for 3 days, in order to remove the salts. The extracted WSP were freeze-dried overnight, and visualised using an XL30 ESEM scanning electron microscope.

Monosaccharide composition of the extracted polysaccharides was determined after acid hydrolysis. $2 \mathrm{mg}$ of lyophilized WSP was mixed with $0.5 \mathrm{ml}$ of trifluoroacetic acid $(2 \mathrm{~N})$ and heated at $120^{\circ} \mathrm{C}$ for 2,4 , and $6 \mathrm{~h}$. The mixture was then completely dried under nitrogen flow, then solubilised in $100 \mu \mathrm{l}$ distilled water. The obtained hydrolysate ( $5 \mu \mathrm{l}$ from each solution) was then analyzed with thin layer chromatography using silica gel plate 60 F254 (Millipore) as previously described (Ben Jeddou et al., 2014). Glucose, arabinose, mannose, xylose, rhamnose, galactose and galacturonic acid were used as standards for compounds identification ( $5 \mu 1$ from each standard solution at $4 \mathrm{mg} \mathrm{ml}^{-1}$ ). A mixture of chloroform / acetic acid / water $(6: 7: 1 \mathrm{v} / \mathrm{v})$ was used as the mobile phase. After the separation of the compounds, the plate was dried and pulverised with a mixture of absolute ethanol / concentrated sulphuric acid $(95: 5 \mathrm{v} / \mathrm{v})$. Drying at $110^{\circ} \mathrm{C}$ for $10 \mathrm{~min}$ allowed the revelation of the different spots.

Uronic acid content was determined using the carbazole method (Bitter and Muir, 1962) with slight modifications. $200 \mu \mathrm{l}$ of a solution of $\mathrm{S} 1(0.025 \mathrm{M}$ sodium tetraborate in sulphuric acid) was mixed with $40 \mu$ of WSP solution $\left(10 \mathrm{mg} \mathrm{ml}^{-1}\right)$. The mixture was then vortexted and incubated for $15 \mathrm{~min}$ at $100^{\circ} \mathrm{C}$, followed by cooling at $4^{\circ} \mathrm{C}$. The second step consisted of adding $8 \mu \mathrm{l}$ of $0.125 \%$ carbazole solution prepared in absolute ethanol. The mixture was 
then vortexed and incubated as previously described. The absorbance was measured at $490 \mathrm{~nm}$ and uronic acid content was determined using a standard curve prepared under the same conditions with polygalacturonic acid standard.

The absorption spectrum of lyophilised WSP was obtained using FTIR (Fourier transform infrared) spectroscopy (Analect Instrument fx-6 160) and was compared to FTIR spectra of citrus peel pectin, cellulose, and beechwood xylan. $1 \mathrm{mg}$ from each sample was mixed with 100 $\mathrm{mg} \mathrm{KBr}$ and the transmission (\%) was recorded between 450 and $4000 \mathrm{~cm}^{-1}$.

The water activity (Aw) of WSP was assessed using a Novasina AW SPRINT TH-500 instrument (Switzerland). The measurement consisted of introducing lyophilized WSP to the instrument capsule and determining the $\mathrm{Aw}$ at $25^{\circ} \mathrm{C}$.

The ability of WSP to scavenge free radicals was determined using the synthetic free radical compound DPPH, according to (Bersuder et al., 1998) with slight modifications. Different amounts of WSP (3 $\mathrm{mg}$ to $50 \mathrm{mg}$ ) were prepared in $500 \mu \mathrm{l}$ of distilled water, and then mixed with $125 \mu \mathrm{l}$ of DPPH solution ( $0.02 \%$ in ethanol) and $375 \mu \mathrm{l}$ of absolute ethanol. All tubes were then shaken and incubated for $60 \mathrm{~min}$ in the dark at room temperature. The scavenging activity was recorded at $517 \mathrm{~nm}$ using a Shimadzu UV/VIS mini 1240 spectrophotometer. The absorption at $517 \mathrm{~nm}$ of the DPPH in its radical form decreases in the presence of an anti-radical compound $\left(A_{\text {sample }}\right)$. For each WSP concentration, a blank was performed using the same amount of WSP, without DPPH $\left(A_{\text {blank }}\right)$. A control experiment was performed by mixing $125 \mu \mathrm{l}$ of DPPH solution and $875 \mu \mathrm{l}$ of ethanol under the same conditions, and the absorbance was recorded as $\left(A_{\text {control }}\right)$. The free radical scavenging activity (\% inhibition) was then calculated as follows:

$$
\text { Inhibition }=\frac{A_{\text {control }}+A_{\text {blank }}-A_{\text {sample }}}{A_{\text {control }}} 100 .
$$

Total antioxidant activity of WSP was assayed as described previously (Koubaa et al., 2015), with slight modifications. Different amounts of WSP $(0.1$ to $50 \mathrm{mg})$ were mixed with $1 \mathrm{ml}$ of reagent solution $(0.6 \mathrm{M}$ sulphuric acid, $28 \mathrm{mM}$ sodium phosphate and $4 \mathrm{mM}$ ammonium molybdate). The mixtures were adjusted to $1.1 \mathrm{ml}$ with distilled water and incubated for $90 \mathrm{~min}$ at $90^{\circ} \mathrm{C}$. After cooling to room temperature, the absorbance was measured at $695 \mathrm{~nm}$ and the total antioxidant activity was expressed as ascorbic acid equivalent using a standard curve previously established. A mixture containing $1 \mathrm{ml}$ of reagent and $100 \mu \mathrm{l}$ of distilled water was incubated under the same conditions and used as blank.

Reducing power capacity was measured according to Yildirim et al. (2001). A mixture of $0.5 \mathrm{ml}$ of a solution containing $0.5 \mathrm{mg}$ to $50 \mathrm{mg}$ WSP, $1.25 \mathrm{ml}$ phosphate buffer $(0.2 \mathrm{M}, \mathrm{pH} 6.6)$ and $1.25 \mathrm{ml}$ potassium ferricyanide $(1 \%$ in water, $\mathrm{w} / \mathrm{v}$ ) was incubated at $50^{\circ} \mathrm{C}$ for $20 \mathrm{~min}$. After cooling to room temperature, $1 \mathrm{ml}$ of trichloroacetic acid $(10 \%$ in water, w/v) was added to the reaction mixture. After $10 \mathrm{~min}$ centrifugation at 3000 r.p.m., $1.5 \mathrm{ml}$ of the supernatant was mixed with $1.5 \mathrm{ml}$ of distilled water and $100 \mu \mathrm{l}$ of fresh ferric trichloride $(0.1 \%$ in water, $w / v)$. The reaction mixture was shaken and its absorbance was measured at $700 \mathrm{~nm}$ against a blank (water was used instead of WSP solution). The absorbance is proportional to the reduction capacity of the sample. As reference curves, the reducing capacities of butylated hydroxyanisole (BHA) and ascorbic acid (0.01 and $50 \mathrm{mg}$ ) were determined under the same conditions.

All experiments were carried out in triplicate, and average values with standard deviation (SD) errors are reported. Significant differences between the results were calculated by multiple sample comparison of the means (ANOVA), with a significance level of $p<0.05$, using the software SPSS Version 22 (IBM ${ }^{\circledR}$ SPSS ${ }^{\circledR}$ Statistics, USA).

\section{RESULTS AND DISCUSSION}

Table 1 shows the chemical composition of $O$. stricta Haw. fruit peels determined as described in the material and methods section. The obtained dry matter for $O$. stricta was similar to $O$. ficus indica (9.67\%) (Nebbache et al., 2009). Protein content, determined by Kjeldahl and Bradford methods, revealed no significant differences with an average of $3.7 \pm 0.07 \%$, dry matter basis. In general, opuntia has low protein content (3.2 to $5.0 \%$, dry matter basis) (Tibe et al., 2008), and our results were concordant with protein content found in $O$. joconostle (3.22\%) (Reyes-Agüero et al., 2006). However, lower amounts were recorded for $O$. ficus indica $(1.45 \%)$ (Nebbache et al., 2009) and O. matudae (1.65\%) (Guzmán-Maldonado et al., 2010). Lipid content in O. stricta fruit peels, determined by Soxhlet method $(1.85 \pm 0.37 \%)$, was comparable to the

T a b l e 1. Chemical composition of Opuntia stricta Haw. fruit peels

\begin{tabular}{lc}
\hline Parameter & Value \\
\hline Dry matter (\%) & $11.33 \pm 0.47$ \\
Proteins (\%) & $3.77 \pm 0.11$ \\
Kjeldahl method & $3.63 \pm 0.13$ \\
Bradford method & $1.85 \pm 0.37$ \\
Lipids (\%) & $27.25 \pm 0.14$ \\
Total sugars (\%) & $3.115 \pm 0.035$ \\
Ash (\%) & \\
Minerals (mg100 g-1 dry matter) & 722.18 \\
Magnesium & 6280 \\
Calcium & 1399 \\
Sodium &
\end{tabular}


one obtained for $O$. ficus indica (2.43\%) (El Kossori et al., 1998). The total sugars content recorded for $O$. stricta fruit peels was $27.25 \pm 0.14 \%$. No data have been reported in literature describing the total sugar content in opuntia fruit peels. Total ash was not significantly different from the fruit peels of $O$. ficus indica (3.05\%) (Nebbache et al., 2009), however, higher mineral contents were found (Table 1). In fact, it has been shown that $O$. ficus indica fruit peels contain: $15.7,15.2$, and $1.1 \mathrm{mg} \mathrm{ml}^{-1}$ calcium, magnesium, and sodium, respectively (Nebbache et al., 2009). For $O$. matudae, the mineral contents recorded were: 1.41 , and $0.51 \mathrm{~g} \mathrm{ml}^{-1}$ calcium and magnesium, respectively (GuzmánMaldonado et al., 2010).

Water-soluble polysaccharides (Fig. 1) were extracted from O. stricta Haw. fruit peels with a yield of 7.53 $\pm 0.86 \%$. This yield was higher than that obtained for O. ficus indica $-0.48 \%$ (Majdoub et al., 2010), and O. milpaalta $-0.7 \%$ (Cai et al., 2008), which is probably related to the different extraction procedures.

Water activity is considered as one of the most important parameters in food preservation and processing. It is now generally accepted that aw is more closely related to the microbial, chemical, and physical properties of foods and other natural products than the total moisture content. The obtained aw of WSP was 0.399 , indicating a low and delayed non-enzymatic browning reactions as well as total absence of enzymatic activities and microorganism development (Barbosa-Cánovas et al., 2007).
FTIR spectroscopy was performed on the extracted WSP, between 450 and $4000 \mathrm{~cm}^{-1}$, in order to characterize their structure and purity. As shown in Fig. 2, the characteristic transitions of WSP were observed at 3000-3700, 1500-1770, and 950-1200 $\mathrm{cm}^{-1}$. These features are characteristic of polysaccharidic structure. Similar results have been reported previously (Sila et al., 2014b; Wu, 2009; Yao et al., 2003). The peak at $3398 \mathrm{~cm}^{-1}$ represents the stretching of the hydroxyl groups. The small band at $2922 \mathrm{~cm}^{-1}$ is attributed to $\mathrm{C}-\mathrm{H}$ stretching and bending vibrations, as previously reported (Sila et al., 2014b). Furthermore, the peak observed at $1634 \mathrm{~cm}^{-1}$ is due to the stretching vibrations of $\mathrm{C}-\mathrm{O}$ bonds. The bands at $1073 \mathrm{~cm}^{-1}$ and $1039 \mathrm{~cm}^{-1}$ indicate the presence of pyranose units (Hua et al., 2014; Sila et al., 2014b; Zhao et al., 2005). The comparison between WSP spectra and the performed standards - citrus peel pectin, cellulose and beechwood xylan - shows similar spectra, indicating the polysaccharidic structure of WSP as well as its purity. Similar spectrum was observed for O. ficus indica peel polysaccharides (Majdoub et al., 2001).

The chemical composition of WSP was assessed with thin layer chromatography (Fig. 3), using monosaccharides as standards (glucose, arabinose, mannose, xylose, rhamnose, galactose and galacturonic acid). The WSP hydrolysates, after $2 \mathrm{~h}, 4 \mathrm{~h}$ and $6 \mathrm{~h}$ acidic hydrolysis, were analyzed. The results obtained show that WSP are mainly composed of rhamnose, galactose and galacturonic acid. Minor monosaccharides (glucose, arabinose and mannose) were also present even after $2 \mathrm{~h}$ hydrolysis. However, two

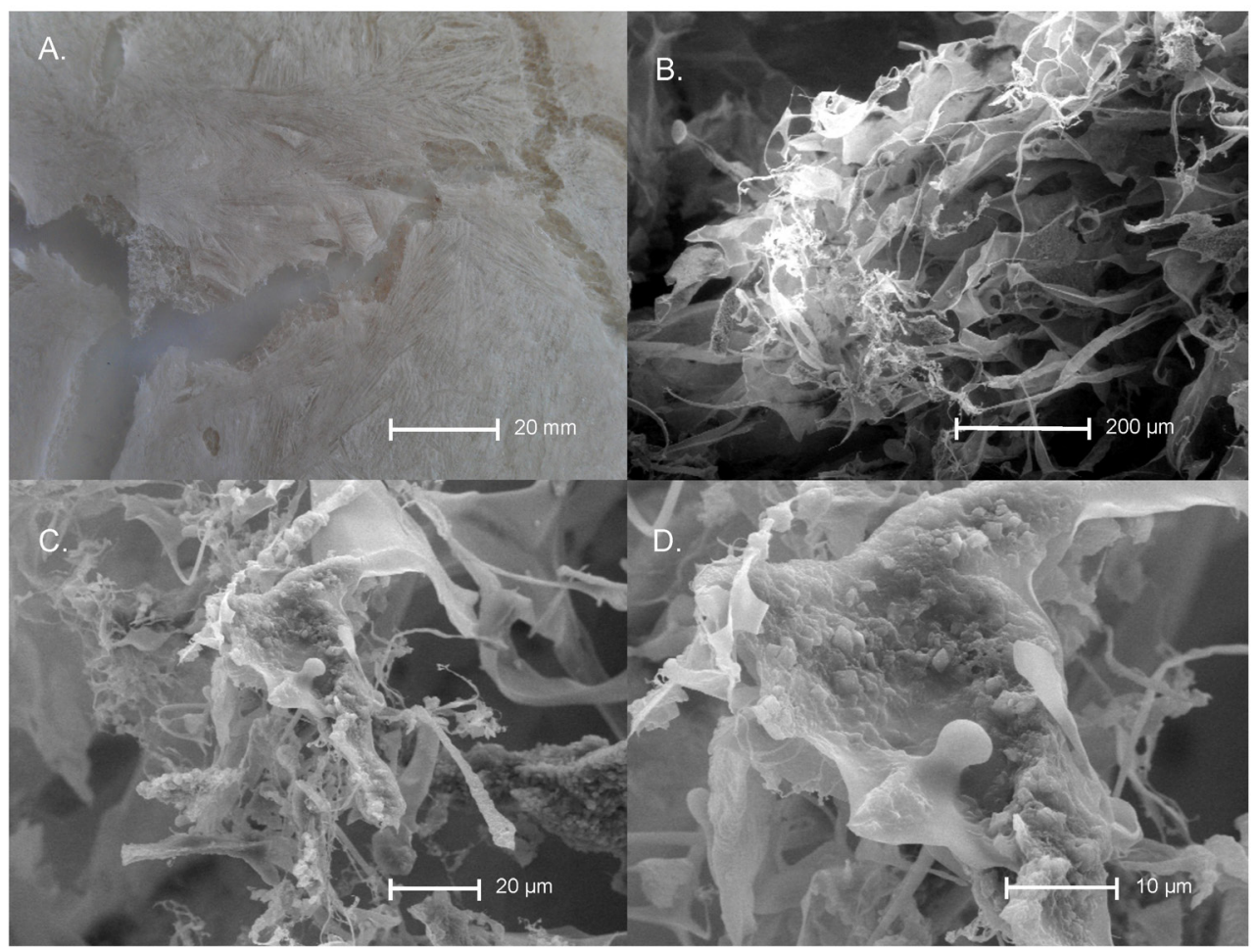

Fig. 1. A - lyophilised water-soluble polysaccharides extracted from Opuntia stricta Haw. fruit peels, B, C, D - scanning electron microscopy of the lyophilised WSP, at 150x, 1000x and 2500x magnification, respectively. 


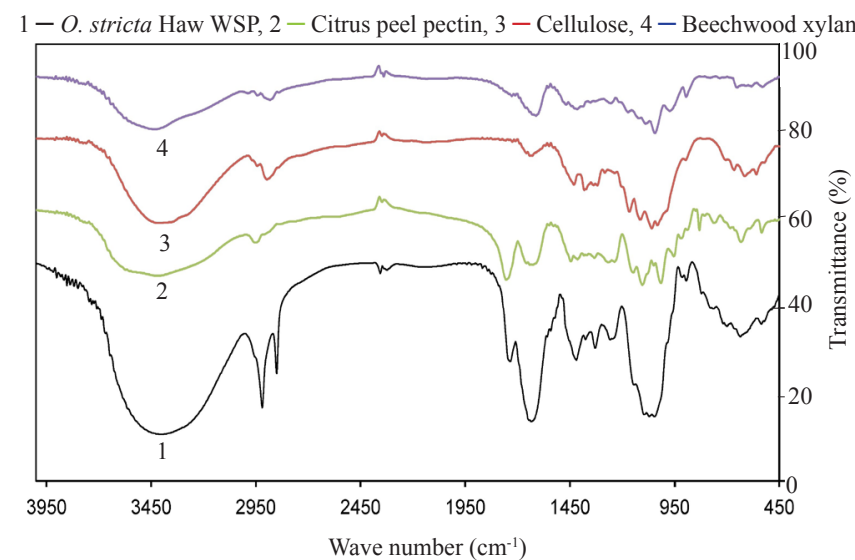

Fig. 2. FTIR spectroscopy of water-soluble polysaccharides extracted from Opuntia stricta Haw. fruit peels (WSP), citrus peel pectin, cellulose, and beechwood xylan. Spectra were performed in transmittance $(\%)$ between 450 and $4000 \mathrm{~cm}^{-1}$.

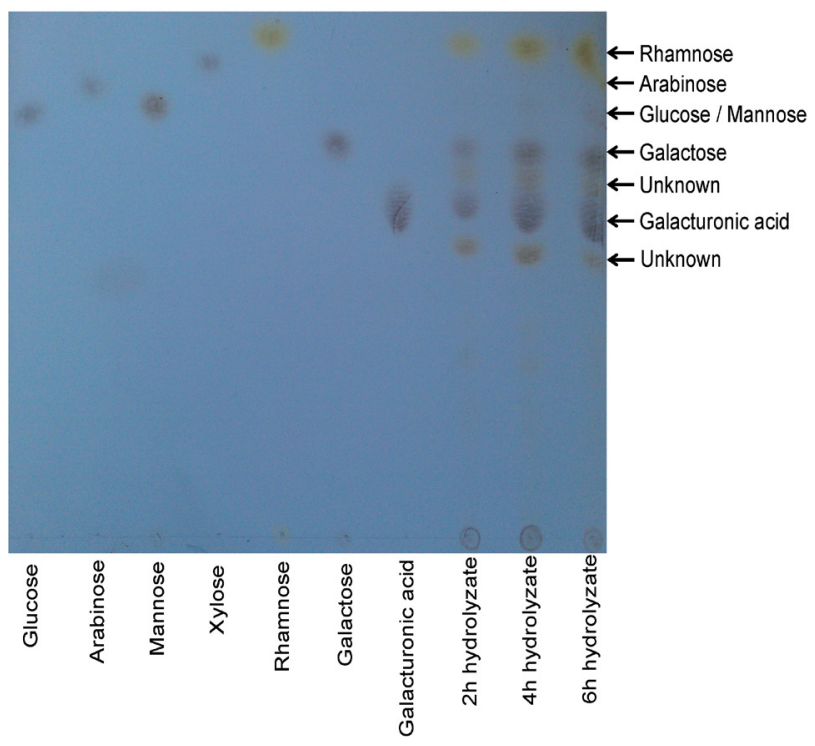

Fig. 3. Thin layer chromatography after 2,4 , and $6 \mathrm{~h}$ acidic hydrolysis of WSP. Spots were identified using sugar standards. The experiment was performed in duplicate. spots were not identified, corresponding probably to other monosaccharides or oligosaccharides after partial hydrolysis. The WSP composition was similar to that obtained for O. ficus indica (Majdoub et al., 2010). Uronic acid content in O. stricta Haw. WSP was $26.16 \pm 4.33 \%$, mainly composed of galacturonic acid (Fig. 3). This content was lower than that observed for $O$. ficus indica peel polysaccharides (65\%) (Forni et al., 1994), and higher than that found in dietary fibre containing material from olive mill wastewater $(3.3 \mathrm{~g} / 100 \mathrm{~g})$ (Galanakis et al., 2010).

DPPH (2,2-diphenyl-1-picrylhydrazyl) scavenging assayis the oldest indirect method for determining the antioxidant activity. In the DPPH assay, antioxidant molecules are able to reduce the stable radical DPPH to the yellow-coloured diphenyl-picrylhydrazine. In the presence of a hydrogendonating antioxidant, the DPPH is reduced, leading to the formation of the non-radical form - DPPH-H (Gülçin, 2012). The antioxidant activity of WSP was determined by their DPPH radical scavenging activity (Fig. 4). The extracted polysaccharides showed concentration-dependent DPPH radical scavenging activity and good antioxidant capacities compared to BHA and ascorbic acid, used as reference molecules. The highest radical scavenging activity values were $94.9,93$ and $96.8 \%$ for WSP, BHA and ascorbic acid, respectively, at $50 \mathrm{mg} \mathrm{ml}^{-1}$. The half inhibition concentration $\left(\mathrm{IC}_{50}\right.$ ) values of WSP, BHA and ascorbic acid were also determined. In general, the lowest $\mathrm{IC}_{50}$ corresponds to the highest DPPH scavenging activity. $\mathrm{The} \mathrm{IC}_{50}$ values were $6.5 \mathrm{mg} \mathrm{ml}^{-1}$ for WSP and $3 \mathrm{mg} \mathrm{ml}^{-1}$ for BHA and ascorbic acid. The $\mathrm{IC}_{50}$ of WSP was lower than those of other polysaccharides reported in literature ( $e g$ polysaccharides extracted from guara fruits with $\mathrm{IC}_{50}$ of $\left.10.8 \mathrm{mg} \mathrm{ml}^{-1}\right)$ (Hua et al., 2014). These results suggest that WSP represent strong electron donors and could react with free radicals to convert them to more stable products and terminate the radical chain reaction.

The total antioxidant capacity (TAC) is based on the reduction of phosphomolybdate by the antioxidant molecule. The subsequent reaction is the formation of a green phosphate/Mo (V) complex, at acidic $\mathrm{pH}$, which absorbs at

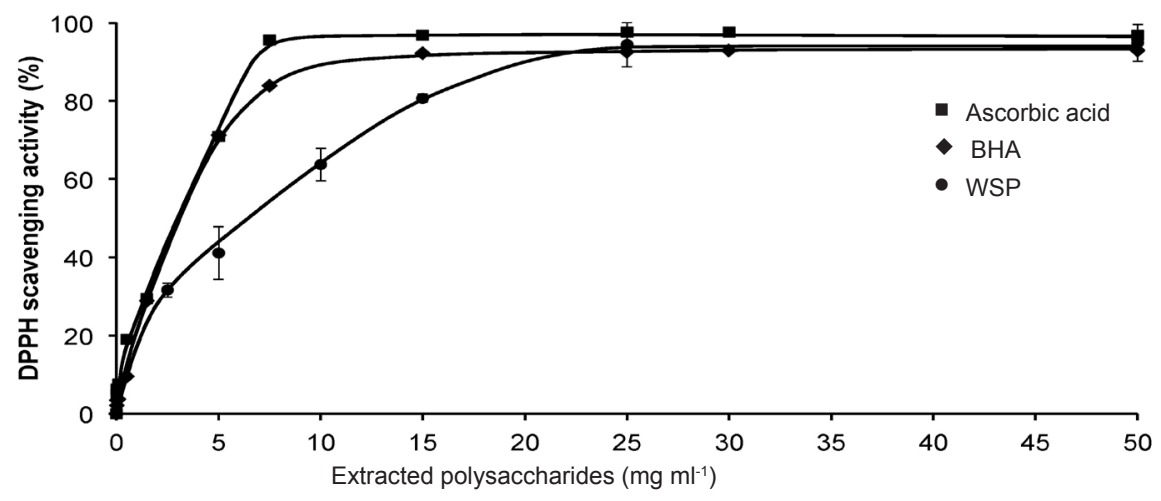

Fig. 4. DPPH free radical scavenging activity of the extracted polysaccharides from $O$. stricta Haw. fruit peels. BHA and ascorbic acid were used as reference molecules. Values are the average of triplicate experiments \pm SD. 


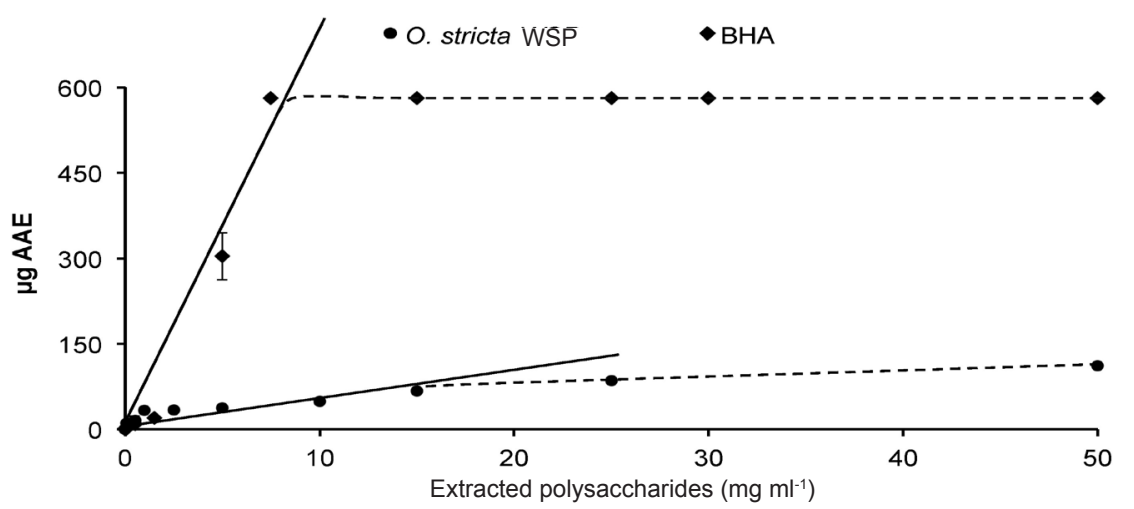

Fig. 5. Total antioxidant activity of the extracted polysaccharides from $O$. stricta Haw. fruit peels. Results are expressed in $\mu \mathrm{g}$ ascorbic acid equivalent (AAE) and BHA was used as a reference molecule. Values are the average of triplicate experiments \pm SD.

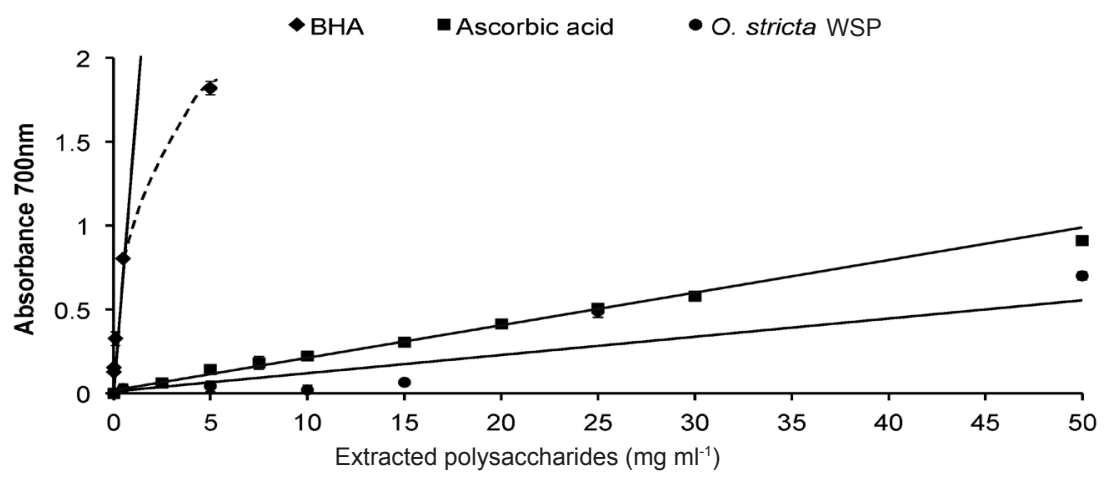

Fig. 6. Reducing power activity of the extracted polysaccharides from O. stricta Haw. fruit peels. BHA and ascorbic acid were used as reference molecules. Values are the average of triplicate experiments $\pm \mathrm{SD}$.

$695 \mathrm{~nm}$. The total antioxidant activities of WSP and BHA were determined and expressed as ascorbic acid equivalent (AAE) (Fig. 5). The results obtained showed an increase of the antioxidant activity proportionally to the concentration of the analyzed sample. $50 \mathrm{mg}$ of WSP were equivalent to $100 \mu \mathrm{g}$ ascorbic acid, in terms of TAC. At $7.5 \mathrm{mg}$ BHA, the measured absorbance exceeded the quantification limits of the spectrophotometer and stabilised at $600 \mu \mathrm{g}$ equivalent ascorbic acid. Despite the significant differences between WSP and BHA, these results show the efficiency of the extracted polysaccharides as a natural antioxidant.

The WSP ability to reduce $\mathrm{Fe}^{3+}$ to $\mathrm{Fe}^{2+}$ was determined by measuring the formation of Perl Prussian blue at $700 \mathrm{~nm}$ (Fig. 6). The reducing power of WSP was increasing proportionally to the sample concentration, from $13 \mathrm{mg} \mathrm{ml}^{-1}$. At $50 \mathrm{mg} \mathrm{ml}^{-1}$, the absorbance values of WSP and ascorbic acid were 0.7 and 0.91 , respectively. The absorbance of BHA at this concentration exceeded 2, showing a saturation behaviour. Despite the presence of reducing capacity, the values obtained remain lower than those of other polysaccharides such as those extracted from almond ( 1.5 at $\left.5 \mathrm{mg} \mathrm{ml}^{-1}\right)$ and pistachio (1.74 at $5 \mathrm{mg} \mathrm{ml}^{-1}$ ) juice processing by-products (Sila et al., 2014b), as well as from mushroom (3.4 at $20 \mathrm{mg} \mathrm{ml}^{-1}$ ) (Kozarski et al., 2012).

\section{CONCLUSIONS}

1. The structure and the chemical composition of Opuntia stricta Haw. peels were investigated, revealing similarities with extracted water-soluble polysaccharides compared to those obtained from Opuntia ficus-indica fruit peels.

2. Afterwards, it was demonstrated that the extracted polysaccharides were efficient natural antioxidants tested in vitro through 2,2-diphenyl-1-picrylhydrazyl free radical scavenging activity, total antioxidant activity and reducing power capacity.

3. The extracted water-soluble polysaccharides could therefore be used as natural food additives, replacing synthetic antioxidants, and resolving thus the environmental problems related with their disposal.

\section{REFERENCES}

AFNOR, 1977. Determination of nitrogen for the calculation of crude protein content. Association Française de normalisation, Paris, France.

AFNOR, 1981. Recueil de normes françaises des corps gras, graines oléagineuses, produits dérivés. Association française de normalisation, Courbevoie, France. 
AFNOR, 1982. Recueil de normes françaises des produits dérivés des fruits et légumes, jus de fruits. Association Française de normalisation, Paris, France.

Barbosa-Cánovas G.V., Fontana A.J., Schmidt S.J., and Labuza T.P., 2007. Water activity in foods: fundamentals and applications. Blackwell Publishing, Ames, IA, USA.

Belton P.S., Gil A.M., Webb G.A., Rutledge D., Dilas S.M., Ćanadanović-Brunet J.M., Ćetković G.S., and Tumbas V.T., 2003. Antioxidative activity of some herbs and spices - A review of ESR studies. In: Magnetic Resonance in Food Science, Special Publication. Cambridge, UK, Royal Society of Chemistry, 157, 110-120.

Ben Jeddou K., Maktouf S., Ghazala I., Frikha D., Ghribi D., Ellouz Ghorbel R., and Nouri-Ellouz O., 2014. Potato peel as feedstock for bioethanol production: A comparison of acidic and enzymatic hydrolysis. Ind. Crops Prod., 52, 144-149.

Bersuder P., Hole M., and Smith G., 1998. Antioxidants from a heated histidine-glucose model system. I: Investigation of the antioxidant role of histidine and isolation of antioxidants by high-performance liquid chromatography. J. Am. Oil Chem. Soc., 75, 181-187.

Bitter T. and Muir H.M., 1962. A modified uronic acid carbazole reaction. Anal. Biochem., 4, 330-334.

Bradford M.M., 1976. A rapid and sensitive method for the quantitation of microgram quantities of protein utilizing the principle of protein-dye binding. Anal. Biochem., 72, $248-254$

Cai W., Gu X., and Tang J., 2008. Extraction, purification, and characterization of the polysaccharides from Opuntia milpa alta. Carbohydr. Polym., 71, 403-410.

Caili F., Haijun T., Tongyi C., Yi L., and Quanhong L., 2007. Some properties of an acidic protein-bound polysaccharide from the fruit of pumpkin. Food Chem., 100, 944-947.

Chen H., Zhang M., Qu Z., and Xie B., 2008. Antioxidant activities of different fractions of polysaccharide conjugates from green tea (Camellia sinensis). Food Chem., 106, 559-563.

Dent M., Dragović-Uzelac V., Penić M., Brnčić M., Bosiljkov T., and Levaj B., 2013. The effect of extraction solvents, temperature and time on the composition and mass fraction of polyphenols of dalmatian wild sage (Salvia officinalis L.). Food Technol. Biotechnol., 51, 84-91.

Ding X., Zhu F., and Gao S., 2012. Purification, antitumour and immunomodulatory activity of water-extractable and alkaliextractable polysaccharides from Solanum nigrum L. Food Chem., 131, 677-684.

Dubois M., Gilles K.A., Hamilton J.K., Rebers P.A., and Smith F., 1956. Colorimetric method for determination of sugars and related substances. Anal. Chem., 28, 350-356.

EI Kossori R.L., Villaume C., El Boustani E., Sauvaire Y., and Méjean L., 1998. Composition of pulp, skin and seeds of prickly pears fruit (Opuntia ficus indica sp.). Plant Foods Hum. Nutr., 52, 263-270.

Forni E., Penci M., and Polesello A., 1994. A preliminary characterization of some pectins from quince fruit (Cydonia oblonga Mill.) and prickly pear (Opuntia ficus indica) peel. Carbohydr. Polym., 23, 231-234.

Galanakis C.M., 2011. Olive fruit dietary fiber: components, recovery and applications. Trends Food Sci. Technol., 22, 175-184.
Galanakis C.M., 2012. Recovery of high added-value components from food wastes: Conventional, emerging technologies and commercialized applications. Trends Food Sci. Technol., 26, 68-87.

Galanakis C.M., 2013. Emerging technologies for the production of nutraceuticals from agricultural by-products: A viewpoint of opportunities and challenges. Food Bioprod. Process., 91, 575-579.

Galanakis C.M. and Schieber A., 2014. Editorial of Special Issue on Recovery and utilization of valuable compounds from food processing by-products. Food Res. Int., Recovery and Utilization of Valuable Compounds from Food Processing by-products, 65, Part C, 299-300.

Galanakis C.M., Tornberg E., and Gekas V., 2010. A study of the recovery of the dietary fibres from olive mill wastewater and the gelling ability of the soluble fibre fraction. LWT Food Sci. Technol., 43, 1009-1017.

Guzmán-MaldonadoS.H., Morales-MontelongoA.L., Mondragón-Jacobo C., Herrera-Hernández G., Guevara-Lara F., and Reynoso-Camacho R., 2010. Physicochemical, nutritional, and functional characterization of fruits xoconostle (Opuntia matudae) pears from central-México region. J. Food Sci., 75, C485-C492.

Gülçin İ., 2012. Antioxidant activity of food constituents: an overview. Arch. Toxicol., 86, 345-391.

Habibi Y., Mahrouz M., Marais M.-F., and Vignon M.R., 2004. An arabinogalactan from the skin of Opuntia ficus-indica prickly pear fruits. Carbohydr. Res., 339, 1201-1205.

Hua D., Zhang D., Huang B., Yi P., and Yan C., 2014. Structural characterization and DPPH. radical scavenging activity of a polysaccharide from Guara fruits. Carbohydr. Polym., 103, 143-147.

Jorhem L., 2000. Determination of metals in foods by atomic absorption spectrometry after dry ashing: NMKL Collaborative Study. J. AOAC Int., 83, 1204-1211.

Koubaa M., Driss D., Bouaziz F., Ellouz Ghorbel R., and Ellouz Chaabouni S., 2015. Antioxidant and antimicrobial activities of solvent extract obtained from rocket (Eruca sativa L.) flowers. Free Radicals Antioxidants, 5, 29-34.

Kozarski M., Klaus A., Nikšić M., Vrvić M.M., Todorović N., Jakovljević D., and Van Griensven L.J.L.D., 2012. Antioxidative activities and chemical characterization of polysaccharide extracts from the widely used mushrooms Ganoderma applanatum, Ganoderma lucidum, Lentinus edodes and Trametes versicolor. J. Food Compos. Anal., 26, 144-153.

Krichen F., Karoud W., Sila A., Abdelmalek B.E., Ghorbel R., Ellouz-Chaabouni S., and Bougatef A., 2015. Extraction, characterization and antimicrobial activity of sulfated polysaccharides from fish skins. Int. J. Biol. Macromol., 75, 283-289.

Leung M.Y.K., Liu C., Koon J.C.M., and Fung K.P., 2006. Polysaccharide biological response modifiers. Immunol. Lett., 105, 101-114.

Madhavi D.L., Deshpande S.S., and Salunkhe D.K., 1996. Food antioxidants technological, toxicological, and health perspectives. Dekker Press, New York, USA.

Majdoub H., Picton L., Cerf D. Le, and Roudesli S., 2010. Water retention capacity of polysaccharides from prickly pear nopals of Opuntia ficus-indica and Opuntia litoralis: physical-chemical approach. J. Polym. Environ., 18, 451-458. 
Majdoub H., Roudesli S., and DerataniA., 2001. Polysaccharides from prickly pear peel and nopals of Opuntia ficus-indica: extraction, characterization and polyelectrolyte behaviour. Polym. Int., 50, 552-560.

Mokni Ghribi A., Sila A., Maklouf Gafsi I., Blecker C., Danthine S., Attia H., Bougatef A., and Besbes S., 2015. Structural, functional, and ACE inhibitory properties of water-soluble polysaccharides from chickpea flours. Int. J. Biol. Macromol., 75, 276-282.

Nebbache S., Chibani A., Chadli R., and Bouznad A., 2009. Chemical composition of Opuntia ficus-indica (L.) fruit. African J. Biotechnol., 8, 1623-1624.

Obón J.M., Castellar M.R., Alacid M., and Fernández-López J.A., 2009. Production of a red-purple food colorant from Opuntia stricta fruits by spray drying and its application in food model systems. J. Food Eng., 90, 471-479.

Polya G.M., 2003. Biochemical targets of plant bioactive compounds: a pharmacological reference guide to sites of action and biological effects. Taylor Francis, London, New York.

Reyes-Agüero J.A., Aguirre R.J.R., and Valiente-Banuet A., 2006. Reproductive biology of opuntia: A review. J. Arid Environ., 64, 549-585.

Roselló-Soto E., Galanakis C.M., Brnčić M., Orlien V., Trujillo F.J., Mawson R., Knoerzer K., Tiwari B.K., Barba F.J., 2015. Clean recovery of antioxidant compounds from plant foods, by-products and algae assisted by ultrasounds processing. Modeling approaches to optimize processing conditions. Trends Food Sci. Technol., 42(2), 134-149.

Sila A., Bayar N., Ghazala I., Bougatef A., Ellouz-Ghorbel R., and Ellouz-Chaabouni S., 2014a. Water-soluble polysaccharides from agro-industrial by-products: functional and biological properties. Int. J. Biol. Macromol., 69, 236-243.

Sila A., Sayari N., Balti R., Martinez-Alvarez O., NedjarArroume N., Moncef N., and Bougatef A., 2014b. Biochemical and antioxidant properties of peptidic fraction of carotenoproteins generated from shrimp by-products by enzymatic hydrolysis. Food Chem., 148, 445-452.
Sinha A.K., Sharma U.K., and Sharma N., 2008. A comprehensive review on vanilla flavor: extraction, isolation and quantification of vanillin and others constituents. Int. J. Food Sci. Nutr., 59, 299-326.

Šic Žlabur J., Voća S., Dobričevic N., Brnčić M., Dujmić F., and Rimac-Brnčić S., 2015. Optimization of ultrasound assisted extraction of functional ingredients from Stevia rebaudiana Bertoni leaves. Int. Agrophys., 29, 231-237.

Tibe O., Modise D.M., and Mogotsi K.K., 2008. Potential for domestication and commercialization of hoodia and opuntia species in Botswana. African J. Biotechnol., 7, 1199-1203.

Warrand J., 2006. Healthy polysaccharides - The next chapter in food products. Food Technol. Biotechnol., 44, 355-370.

Wijngaard H., Hossain M.B., Rai D.K., and Brunton N., 2012. Techniques to extract bioactive compounds from food byproducts of plant origin. Food Res. Int., 46, 505-513.

Wu C.-S., 2009. Renewable resource-based composites of recycled natural fibers and maleated polylactide bioplastic: Characterization and biodegradability. Polym. Degrad. Stab., 94, 1076-1084.

Yao F., Chen W., Wang H., Liu H., Yao K., Sun P., Lin H., 2003. A study on cytocompatible poly(chitosan-g-l-lactic acid). Polymer (Guildf), 44, 6435-6441.

Yeddes N., Chérif J.K., Guyot S., Sotin H., and Ayadi M.T., 2013. Comparative study of antioxidant power, polyphenols, flavonoids and betacyanins of the peel and pulp of three Tunisian opuntia forms. Antioxidants, 2, 37-51.

Yildirim A., Mavi A., and Kara A.A., 2001. Determination of antioxidant and antimicrobial activities of Rumex crispus L. extracts. J. Agric. Food Chem., 49, 4083-4089.

Zhao G., Kan J., Li Z., and Chen Z., 2005. Structural features and immunological activity of a polysaccharide from Dioscorea opposita Thunb roots. Carbohydr. Polym., 61, 125-131. 